\title{
FAKTOR - FAKTOR YANG MEMENGARUHI MASALAH MENTAL EMOSIONAL REMAJA DI SEKOLAH MENENGAH KEJURUAN (SMK) SWASTA SE KOTA PADANG PANJANG TAHUN 2018
}

\author{
Ainil Fitri ${ }^{1)}$, Meri Neherta ${ }^{2)}$, Heppy Sasmita ${ }^{3)}$ \\ 1) Program Studi DIII Keperawatan Universitas Abdurrab \\ Jl. Riau Ujung No. 73, Pekanbaru, Riau \\ ainil.fitri@univrab.ac.id \\ 2) Fakultas Keperawatan, Universitas Andalas. Padang. Indonesia \\ Email: merineherta@nrs.unand.ac.id \\ 3) Poltekes Kemenkes Padang, Padang Indonesia \\ Email: heppisasmita@yahoo.com
}

\begin{abstract}
Adolescent's uncontrolled mental and emotional conditions can affect adolescent behavior and cause problems in the teen's mental and emotional health. This study aims to find out what are the factors that influence the mental emotional problems of adolescents. The study was conducted in Private Vocational Schools (SMK) throughout the city of Padang Panjang in 2018. The research design was descriptive. The sample amounted to 124 adolescents, with a total sampling technique after screening. The instruments used in this study were the SDQ (Strengths and Difficulties Questionnaire) questionnaire and questionnaires factors that influenced adolescent mental emotional problems. The results of this study indicate that, parenting factors are one of the factors that influence the mental emotional problems of adolescents. Most of the parenting styles applied by the respondents' parents were authoritarian and permissive parenting ie 58.4\%. Both of these parenting styles have an impact on adolescent mental emotional problems, which are on average in the category of risk (risk). Suggestions from this research are expected to soul nurses in the community so that more often establish communication with the school and hold parenting activities in order to create emotional and mental health conditions especially at school.
\end{abstract}

Keywords: Mental Emotional Problems Teens, Family Factors, Peer Factors, School Environtment Factors, Community Environtment Factors

Kondisi mental dan emosional remaja yang tidak terkontrol bisa mempengaruhi tingkah laku remaja dan menyebabkan masalah pada kesehatan mental dan emosional remaja tersebut. Penelitian ini bertujuan untuk mengetahui apa saja faktor - faktor yang mempengaruhi masalah mental emosional remaja. Penelitian dilakukan di Sekolah Menengah Kejuruan (SMK) Swasta se-kota Padang Panjang tahun 2018. Desain penelitian adalah deskriptif. Sampel berjumlah 124 remaja, dengan teknik total sampling setelah skrining. Instrumen yang digunakan dalam penelitian ini adalah kuesioner SDQ (Strengths and Difficulties Questionnaire) dan kuesioner faktor - faktor yang mempengaruhi masalah mental emotional remaja. Hasil penelitian ini menunjukkan bahwa, faktor pola asuh orang tua merupakan salah satu faktor yang banyak mempengaruhi masalah mental emosional remaja. Sebagian besar pola asuh yang diterapkan oleh orang tua responden adalah pola asuh otoriter dan permisif yaitu 58,4\%. Kedua pola asuh ini sangat berdampak pada masalah mental emosional remaja yaitu rata - rata berada pada kategori borderlain (beresiko). Saran dari penelitian ini adalah diharapkan kepada perawat jiwa dikomunitas agar lebih sering menjalin komunikasi dengan pihak sekolah dan mengadakan kegiatan parenting agar tercipta kondisi kesehatan mental dan emosional remja terutama di sekolah.

Kata Kunci: Masalah Mental Emosional Remaja, Faktor Keluarga, Faktor Teman Sebaya, Faktor Lingkungan Sekolah, Faktor Lingkungan Masyarakat 


\section{PENDAHULUAN}

Rentang usia remaja berdasarkan ketentuan WHO adalah $10-19$ tahun. Peraturan Mentri Kesehatan RI nomor 25 tahun 2014 menyatakan bahwa remaja adalah penduduk yang berusia $10-18$ tahun. Sedangkan berdasarkan BKKBN (2015) remaja adalah seseorang yang berusia 10 - 24 tahun dan belum menikah. Perkembangan remaja terdiri dari perkembangan biologis, kognitif, psikososial, mental dan emosional. Perkembangan biologis seperti perkembangan otak dan hormon (Jahja, 2015).

Berdasarkan hasil survey nasional kesehatan berbasis sekolah (SMP dan SMA) yang dilakukan oleh Kementrian Kesehatan Indonesia yang dipublikasikan pada tahun 2015 menyatakan bahwa ada sepuluh faktor perilaku yang beresiko pada kesehatan remaja salah satunya adalah kesehatan mental dan emosional yang terganggu. Dari tiga regional yang di survei yaitu Sumatra, Jawa dan Bali, luar Jawa dan Bali diperoleh hasil $46,01 \%$ pelajar $(39,7 \%$ pelajar lakilaki dan $51,98 \%$ perempuan) mengalami kesepian (loneliness), 42,18\% (38\% pelajar laki - laki, 46,14\% pelajar perempuan) mengalami cemas atau kekhawatiran yang berlebihan, $62,38 \%(57,73 \%$ pelajar lakilaki dan $66,82 \%$ pelajar perempuan) mengalami gangguan emosional yaitu kesepian (loneliness), kekhawatiran yang berlebihan bahkan keinginan untuk bunuh diri.

Data dari KPAI tahun 2016 mencatat anak korban tawuran pelajar 33 orang, anak pelaku tawuran 52 orang, anak korban bulliying 97 orang, anak pelaku bulliying 112 orang, anak korban pungli, anak putus sekolah dll 34 orang, anak sebagai pelaku kekerasan fisik 89 orang, anak sebagai pelaku kekerasan psikis 31 orang, anak sebagai pelaku kekerasan seksual 107 orang, anak pelaku pembunuhan 36 orang, anak pelaku pencurian 32 orang, anak pelaku kecelakaan lalu lintas 51 orang, anak pelaku kepemilikan senjata tajam 17 orang, anak pelaku penculikan 6 orang dan anak sebagai pelaku aborsi sebanyak 33 orang.

Banyak faktor yang dapat memicu timbulnya masalah mental emosional pada remaja yaitu lingkungan keluarga, lingkungan teman sebaya, lingkungan sekolah, lingkungan masyarakat dan sosial media (Santrock, 2012).

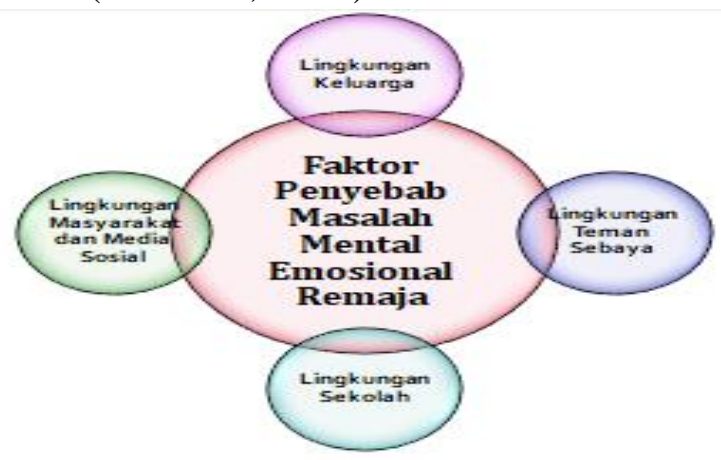

Santrock, 2012

Lingkungan keluarga yang dimaksud disini adalah pola asuh orang tua, keharmonisan keluarga, kedekatan saudara kandung, sosial ekonomi keluarga, dan pendidikan moral.

Pola asuh adalah sikap dan perilaku orang tua dalam membimbing, mendidik, dan melatih anaknya agar dapat berperilaku sesuai dengan yang diharapkan orang tua dan berguna untuk masa depan kehidupan anaknya kelak. Berdasarkan penelitian yang dilakukan oleh (Silitonga, 2015) diperoleh hasil bahwa pola asuh orang tua berpengaruh pada perkembangan emosional remaja dan disarankan agar orang tua harus mampu menyasuaikan tindakan dan pola asuh yang baik agar perkembangan emosional remaja semakin optimal. Jenis pola asuh orang tua dapat dibagi menjadi empat yaitu : pengasuhan otoriter, pengasuhan demokrtatis, pengasuhan mengabaikan, pengasuhan yang menuruti (Krisnatuti, 2012). 
Teman sebaya memiliki peran yang sangat penting bagi perkembangan emosional maupun sosial remaja, bahkan pengaruh peer group lebih dominan dibandingkan pengaruh lingkungan keluarga (Kusumadewi, 2012). Tidak jarang peer group berpotensi menggantikan pengaruh positif dari keluarga dan guru menjadi perilaku menyimpang atau kenakalan remaja. Kelompok teman sebaya yang cenderung dibentuk oleh remaja meliputi kelompok sahabat karib (chums) terdiri dari 2-3 anggota remaja, kemudian kelompok sahabat (cliques) terdiri dari 4-5 orang remaja dan kelompok banyak remaja (crowds) terdiri lebih dari 5 orang remaja atau banyak remaja (Rahmawati, 2013). Kelompok remaja mempunyai orientasi nilai dan norma tersendiri dan kesepakatan yang secara khusus hanya berlaku untuk kelompok tersebut. Penerimaan teman sebaya merupakan hal yang terpenting dalam kehidupan remaja, karena memungkinkan remaja untuk mengembangkan identitas dirinya.

Lingkungan sekolah merupakan lingkungan sosial yang jauh lebih luas dibanding lingkungan sosial dalam keluarga. Lingkungan sekolah terdiri teman sebaya dan guru. Cara mengajar, bersikap dan berinteraksi seorang guru tidak hanya mempengaruhi akademik seorang peserta didik namun juga mempengaruhi perkembangan mental, emosional, sikap, moral, dan spiritual remaja (Gunarsa, 2012). Sekolah menengah lanjutan/atas selayaknya berorientasi komprehensif. Fungsi utama sekolah bukan hanya tempat pengembangan dan pelatihan intelektual. Namun, juga meliputi banyak hal seperti pengembangan sosial, emosional, moral, dan spiritual.

Lingkungan masyarakat adalah lingkungan terluas dari seorang remaja. Sosial budaya yang sudah melekat pada masyarakat sekitar ternyata turut mempengaruhi perkembangan mental emosional remaja (Diananta, 2012). Tuntutan agar remaja mematuhi aturan budaya, nilai dan norma yang berlaku di masyarakat membuat timbulnya rasa cemas, terancam, dan hilangnya rasa kasih sayang di hati remaja. Namun, jika kondisi lingkungan masyarakat ini dapat menempatkan aturannya dengan tepat, hal ini sangat menguntungkan bagi perkembangan mental emosional remaja menjadi lebih terarah. Sehingga remaja bisa bertingkah laku sesuai nilai dan norma yang ada.

Berdasarkan latar belakang dan tinjauan literature diatas peneliti tertarik meneliti tentang factor apa saja yang mempengaruhi masalah mental emosional remaja di SMK Swasta Se- Kota Padang Panjang Tahun 2018.

Adapun tujuan dari penelitian ini adalah untuk mengetahui apa saja faktor yang mempengaruhi masalah mental emosional remaja di SMK Swasta Se- Kota Padang Panjang Tahun 2018.

\section{METODE PENELITIAN}

Penelitian ini menggunakan jenis penelitian kuantitatif dengan desain deskriptif. Penelitian ini dilakukan di SMK Swasta SeKota Padang Panjang. Sample pada penelitian ini adalah 124 orang. Teknik sample yang digunakan adalah total sampling setelah dilakukan screening SDQ terlebih dahulu. Instrument penelitian yang digunakan pada penelitian ini adalah kuesioner terkait faktor - faktor yang mempengaruhi masalah mental emosional remaja yang terdiri dari 21 pertanyaan/ pernyataan. Pengolahan data merupakan bagian dalam rangkaiaan kegiatan yang dilakukan setelah pengumpulan data. Pengolahan data dilakukan dengan system komputerisasi. Langkah - langkah pengolahan data meliputi editing, coding, processing, cleaning, dan tabulating. Analisa data dilakukan secata univariat. 


\section{HASIL DAN PEMBAHASAN}

Distribusi frekuensi responden berdasarkan karakteristik jenis kelamin yaitu laki - laki berjumlah 103 orang $(83,1 \%)$ dan perempuan berjumlah 21 orang $(16,9 \%)$. Berdasarkan hasil penelitian didapatkan bahwa, dari empat faktor yang mempengaruhi masalah mental emosional remaja ada dua faktor yang signifikan mempengaruhi masalah mental emosional remaja di SMK Swasta Se - Kota Padang Panjang pada tahun 2018 yaitu faktor pola asuh orang tua dengan hasil statistik $\mathrm{p}$ value $0,0034(\mathrm{p}<0,05)$ dan faktor lingkungan teman sebaya dengan hasil statistik $\mathrm{p}$ value $0,001(\mathrm{p}<0,05)$.

Hasil penelitian ini menunjukkan bahwa, sebagian besar pola asuh yang diterapkan oleh orang tua adalah pola asuh otoriter dan permisif yaitu 58,4\%. Kedua pola asuh ini sangat berdampak pada masalah mental emosional remaja yaitu rata - rata berada pada kategori borderlain.

Kategori boederline berarti bahwa remaja tersebut berisiko mengalami emosional symptoms, conduct problem, hyperactivity dan peer problem serta berpeluang untuk mengalami masalah psikososial jika tidak ditangani dengan baik. Sementara dari penelitian ini juga didapatkan bahwa ada beberapa remaja yang memiliki masalah mental emosional pada kategori abnormal.

Jika kita lihat hasil dari analisa kuesioner maka 41 responden memiliki pola asuh otoriter dan 22 responden memiliki pola asuh permisif. Pola asuh otoriter yaitu pola asuh yang bersifat pemaksaan, keras dan kaku dimana orang tua akan membuat berbagai aturan yang harus dipatuhi oleh anak tanpa mau tahu perasaan sang anak. Orang tua akan emosi dan marah jika anak melakukan hal yang tidak sesuai dengan yang diinginkan oleh orang tuanya. Contohnya, orang tua yang otoriter mungkin berkata, " lakukan dengan caraku atau tak usah “. Kebanyakan anak dari orang tua yang otoriter mungkin saja mengalami masalah emosional (Santrock, 2012).

Hal ini sejalan dengan pendapat yang dikemukakan oleh Santrock (2012) ia mengatakan bahwa kebanyakan anak dari orang tua yang otoriter memiliki peluang lebih besar mengalami masalah emosional.

Pola asuh Permisif yaitu pola asuh yang ditandai dengan adanya kebebasan tanpa batas pada anak untuk berperilaku sesuai dengan kenginannya sendiri. Orang tua tidak pernah memberi aturan atau pengarahan kepada anak (Hoskins, 2014). Semua keputusan diserahkan kepada anak tanpa pertimbangan orang tua sehingga anak tidak tahu apakah perilakunya itu sudah benar atau salah akibatnya anak akan berperilaku sesuai dengan keinginannya sendiri, tidak peduli apakah sesuai dengan norma masyarakat atau tidak.

Hoskins (2014) juga mengatakan bahwa pola asuh permisif yang cenderung memberi kebebasan pada anak untuk berperilaku sesuia dengan keinginannya sendiri, tidak peduli apakah perilaku itu sesuai dengan norma masyarakat atau tidak ternyata juga sangat mempengaruhi masalah mental dan emosional remaja. Pendapat ini didukung oleh penelitian Devita (2015) ia mengatakan bahwa dari empat pola asuh orang tua, pola asuh permisif adalah variabel paling berpengaruh terhadap masalah mental emosional remaja.

Selain itu tidak bisa dipungkiri pengaruh dari teman sebaya juga dapat memicu semakin parahnya masalah mental emosional yang dialami remaja. Tidak jarang peer group berpotensi menggantikan pengaruh positif dari keluarga dan guru menjadi perilaku menyimpang atau kenakalan remaja (Ali, 2016).

\section{KESIMPULAN}

Berdasarkan dari penelitian diatas dapat disimpulkan bahwa ada dua faktor yang 
mempengaruhi masalah mental emosional remaja di SMK Swasta Se - Kota Padang Panjang yaitu faktor pol asuh orang tua dan faktor lingkungan teman sebaya.

\section{DAFTAR PUSTAKA}

Ali, M. (2016). Psikologi Remaja Perkembangan Peserta Didik. Jakarta: Bumi Aksara.

BKKBN. (2015). Kajian Profil penduduk Remaja (10-24 tahun) : Ada Apa Dengan Remaja. Policy Brief Puslitbang Kependudukan-BKKBN

Devita, Y. (2015). Hubungan Pola Asuh Orang Tua Dengan Masalah Mental Emosional Remaja Di Kelurahan Tuah Karya Kecamatan Tampan Kota Pekanbaru Provinsi Riau. Tesis Program Studi Magister Keperawatan Fakultas Keperawatan Universitas Andalas. Tidak Dipublikasikan.

Diananta, G. S. (2012). Perbedaan Masalah Mental Dan Emosional Berdasarkan Latar Belakang Pendidikan Agama, Studi Kasus SMP Negeri 21 Semarang dan SMP Islam Al Azhar 14 Semarang. Tugas Akhir Fakultas Kedokteran Universitas Diponegoro. Tidak Dipublikasikan.

Gunarsa, Y. S. D. (2012). Psikologi Remaja (1st ed.). Jakarta: Libri.

Hoskins, D. (2014). Consequences of Parenting on Adolescent Outcomes. Journal Societies, 4(3), 506-531. https://doi.org/10.3390/soc4030506

Jahja, Y. (2015). Psikologi Perkembangan. Jakarta: Prenadamedia Group.

KPAI. (2016). Kasus Pengaduan Anak Berdasarkan Klaster Perlindungan Anak. (46), 2016.

Krisnatuti, D. (2012). Gaya Pengasuhan Oang Tua Interaksi Serta Kelekatan Ayah - Remaja, dan Kepuasan Ayah. Jurnal Ilmu Keluarga dan Konsumen, 5(2) 101 - 109. Bogor: Indonesia.

Kusumadewi. (2012). Hubungan antara
Dukungan Sosial Peer Group dan Kontrol Diri dengan Kepatuhan terhadap Peraturan pada Remaja Putri di Pondok Pesantren Modern Islam Assalaam Sukoharjo. Fakultas Kedokteran Universitas Sebelas Maret.

Rahmawati, A. D. (2013). Psikologi Keluarga: Penanaman Nilai dan Penanganan Konflik Dalam Keluarga (1st ed.). Jakarta: Kencana Prenada Media Group.

Santrock, J. W. (2012). Life - Span Development, Perkembangan Masa Hidup (Edisi Ketigabelas) Jilid I. Jakarta: Erlangga.

Silitonga, R. S. (2015). Hubungan Pola Asuh Orang Tua Dengan Perkembangan Emosional Remaja Di Sekolah Menengah Atas (SMA) Negeri 14 Medan Tahun 2015. Fakultas Keperawatan \& Kebidanan Universitas Sari Mutiara Indonesia .

WHO. (2012). World Health Statistics 2012. World Health Statistics 2012 (Vol. 27). https://doi.org/10.2307/3348165 